\title{
Mid-Latitude Single Station F region Storm Morphology and Forecast
}

\author{
Ljiljana R. CANDER \\ Rutherford Appleton Laboratory, Harwell Oxford, United Kingdom; \\ e-mail: 1jiljana.cander@stfc.ac.uk
}

\begin{abstract}
This paper describes certain aspects of the F region storm morphology based on vertical incidence measurements at single ionosonde station Chilton $\left(51^{\circ} .60^{\prime} \mathrm{N}, 358^{\circ} .70^{\prime} \mathrm{E}\right)$. The topics discussed include requirements for better understanding of the ionospheric $\mathrm{F}$ region morphology and its forecasting under geomagnetically quiet and disturbed conditions. A few common storms during the years of low (1996 and 1997) and high (2000 and 2001) solar activity are considered as well as the Short-Term Ionospheric Forecasting (STIF) method by using two representative examples. The merits are stressed of near-real-time use of data to provide more accurate specification of the geomagnetically disturbed ionosphere and forecast its structure few hours in advance.
\end{abstract}

Key words: ionosphere (mid-latitude F region, ionospheric modelling and forecasting), geomagnetic storms, space weather.

\section{INTRODUCTION}

The ionospheric $\mathrm{F}$ region parameters are highly variable on timescales ranging from decades to seconds with the occurrence of ionospheric storms in the F region associated with geomagnetic storms. Even in its quietest moments, the Sun produces the electromagnetic radiation and the solar wind, which simultaneously affect a variety of geomagnetic and ionospheric phenomena. Many modelling techniques successfully describe long-term ionospheric

Ownership: Institute of Geophysics, Polish Academy of Sciences;

(C) 2016 Cander. This is an open access article distributed under the Creative Commons

Attribution-NonCommercial-NoDerivs license,

http://creativecommons.org/licenses/by-nc-nd/3.0/. 
variations, such as that directly related to the sunspot cycle (IvanovKholodny and Mikhailov 1986, Bilitza 2001, Zolesi and Cander 2014 and references therein). Their results of modelling basic ionospheric parameters are angled towards predicting monthly median values for a given place and time of day. Very often it is possible to predict effectively these values with sufficient accuracy by using only the sunspot number as required input parameter (e.g., Fox and McNamara 1988, Zolesi et al. 1993, Bradley 1995, Hanbaba 1999). Although these long-term predictions give a good estimate of the expected average conditions, often defined as the climatological behaviour of the background ionosphere, there are appreciable day-to-day and hour-to-hour variations of different origins with significant scientific and technological consequences.

The conditions and the mechanisms that lead to the ionospheric variability remain the subject of profound investigations. Over the years, particular attempts have been made to study the results of the internationally coordinated investigations of space environmental disturbances, frequently referred to as space weather disturbances (Cander 2008, Hapgood 2011). In the ionospheric domain of these studies, the focus is on forecasting the geomagnetic storm effect on main $\mathrm{F}$ region parameters to enable extreme conditions to be quantified so that, particularly for telecommunications planning purposes, likely variability boundaries can be defined (Mannucci et al. 2015 and references therein). It is very well known that forecasts are made mostly on the basic of persistence and recurrence that are not always strong enough and/or they are heavily built on an extrapolation of past and prevailing ionospheric conditions (Cander 2003 and references therein). In practical applications this requires an automation of the solar-terrestrial data gathering and processing and on-line forecasting message distribution. There has been ample evidence from different national as well as international research projects that true forecasts of ionospheric disturbances are needed with lead times of up to 24-hours of the present (Hanbaba 1999 and references therein). Very recently, sufficient real-time interplanetary data (e.g., solar-wind parameters) and real-time ionospheric conditions have been obtained to do this effectively (Kamide 2000, Galkin et al. 2012 and references therein). However, the $\mathrm{F}$ region storm morphology has such a complex spatial and temporal structure that requires not only continuous monitoring of high resolution but morphological studies with theoretical and numerical modeling as well (East-wood 2008, Mikhailov et al. 2012, Cander 2015).

Studies of ionospheric parameter variations during geomagnetic storms have been made by a large number of scientists world-wide and summarized in a number of excellent review papers by Matsushita (1959), Rishbeth (1991), Prölss (1995), Buonsanto (1999), Fuller-Rowell et al. (1997), Namgaladze et al. (2000), Mendillo (2006), and Vijaya Lekshmi et al. (2011). 
The quantitative modeling of the ionospheric response to geomagnetic activity was also discussed by Fuller-Rowell et al. (2000a), Pietrella and Perrone (2008), McNamara et al. (2011), and Mukhtarov et al. (2013). There is a long list of papers dealing with ionospheric storm case studies during 23th solar cycle. For example, Musman et al. (1998) and Jakowski et al. (1999) studied the ionospheric total electron content (TEC) during the geomagnetic storm on 10 January 1997 while Cander and Mihajlovic (2005) considered ionospheric spatial and temporal variations during October 2003 storm, among many others. The response of the equatorial ionosphere in the South Atlantic Region to the storm of July 2000 has been described by Basu et al. (2001).

In this paper the solar-terrestrial conditions and ionospheric $\mathrm{F}$ region response surrounding a few geomagnetic storms in 23th solar cycle are examined to illustrate what knowledge is needed to develop a successful forecasting algorithm. The series did not include the strongest storms of the considered period, but just ordinary ones during the low (1996 and 1997) and the high (2000 and 2001) solar activity. Section 2 gives details concerning the storm periods and use of data. In Section 3 it is shown how day-today patterns of the F2 layer critical frequency foF 2 (corresponding to the ionospheric peak electron density $N m \mathrm{~F} 2$ ) can be used to search outstanding science issues in ionospheric $\mathrm{F}$ region storm morphology relevant for its forecasting. Section 4 presents necessary details concerning the current status of $\mathrm{F}$ region prediction and covers two examples of $\mathrm{F}$ region forecasting at Chilton ionosonde station. A summary of the findings and future work appear in Section 5.

\section{STORM PERIODS}

Since the beginning of ionospheric measurements a large number of studies have been conducted on the $\mathrm{F}$ region storm morphology based on electron density data provided by world-wide network of ionosondes. To illustrate some of more recent findings, the behaviour of the daily hourly critical frequency foF 2 measured at Chilton $\left(51^{\circ} .60^{\prime} \mathrm{N}, 358^{\circ} .70^{\prime} \mathrm{E}\right)$, an ionosonde station that has been operating for decades starting at the Slough $\left(51^{\circ} .51^{\prime} \mathrm{N}\right.$, $359^{\circ} .40^{\prime} \mathrm{E}$ ) site in the UK, with data available from 1932 onwards, is analyzed. Results shown in this paper are for August, February, and October representing ionospheric summer, winter, and equinox conditions during low (1996/1997) and high solar activity (2000/2001) with emphasize on the raising phase of solar cycle 23 starting from October 1996 as equinox month of absolute solar minimum. Development of a major storm on the last day of March 2001 is analysed in detail making use of $f o \mathrm{~F} 2$ data from Chilton. This ionospheric characteristic was chosen as best representative of the F region behaviour. 
Table 1

Storm periods considered

\begin{tabular}{|c|c|c|c|c|}
\hline Month & $\begin{array}{l}\text { Monthly } \\
\text { mean } R i\end{array}$ & $\begin{array}{l}\text { Storm period with } \mathrm{Q} \text { days } \\
\text { and D days ranks }\end{array}$ & $\mathrm{SSC}(\mathrm{UT})$ & Max $A p$ index \\
\hline $\begin{array}{c}\text { October } \\
1996 \\
\end{array}$ & $0.9^{*}$ & $20,21,22$ (D2), 23 (D3), 24 & None & 38 on 22 Oct \\
\hline \multirow{2}{*}{$\begin{array}{c}\text { October } \\
2000\end{array}$} & \multirow[b]{2}{*}{100.1} & 2, 3, 4 (D2), 5 (D1), 6 (Q5) & 4 Oct at $07: 00$ & 116 on 5 Oct \\
\hline & & $\begin{array}{l}11,12(\mathrm{Q} 9), 13 \text { (D5), } \\
14 \text { (D3), } 15\end{array}$ & 12 Oct at $22: 28$ & 45 on 14 Oct \\
\hline \multirow{2}{*}{$\begin{array}{c}\text { February } \\
1997\end{array}$} & \multirow[t]{2}{*}{7.6} & $\begin{array}{l}7 \text { (Q5), 8, } 9 \text { (D5), } 10 \text { (D3), } \\
11 \text { (D4) }\end{array}$ & $\begin{array}{l}8 \text { Feb at } 09: 54 \\
9 \text { Feb at } 13: 22 \\
11 \text { Feb at } 04: 58\end{array}$ & $\begin{array}{r}22 \text { on } 8 \text { and } \\
10 \mathrm{Feb}\end{array}$ \\
\hline & & $\begin{array}{l}24,25 \text { (Q9), 26, 27(D2), } \\
28 \text { (D1) }\end{array}$ & None & 37 on $28 \mathrm{Feb}$ \\
\hline \multirow{2}{*}{$\begin{array}{l}\text { February } \\
2000\end{array}$} & \multirow[t]{2}{*}{112.9} & 11,12 (D1), 13, 14 (D3), 15 & $\begin{array}{l}11 \text { Feb at } 02: 58 \\
\text { and at } 23: 52\end{array}$ & 60 on $12 \mathrm{Feb}$ \\
\hline & & 22 (Q6), 23, 24 (D5), 25, 26 & 23 Feb at 11:00 & 30 on $24 \mathrm{Feb}$ \\
\hline $\begin{array}{c}\text { August } \\
1997 \\
\end{array}$ & 24.4 & $\begin{array}{l}2 \text { (Q9), } 3 \text { (D1), 4, } 5 \text { (Q3), } \\
6 \text { (Q2) }\end{array}$ & 3 Aug at $10: 42$ & 21 on 3 Aug \\
\hline $\begin{array}{c}\text { August } \\
2000\end{array}$ & 130.5 & 10,11 (D2), 12 (D1), 13, 14 & 11 Aug at $18: 45$ & 123 on 12 Aug \\
\hline $\begin{array}{l}\text { March } \\
2001\end{array}$ & 114.2 & $29,30,31(\mathrm{D} 1)$ & 31 Mar at 00:52 & 155 on 31 Mar \\
\hline
\end{tabular}

*) The consensus minimum value that occurred in October 1996.

The selected 10 storm events are listed in Table 1. The selection of the geomagnetic storms in Table 1 is based on data published in the SolarGeophysical Data Prompt Report, NOAA, Boulder, USA (http://www.ngdc. noaa.gov), and obtained from the WDC-C2 for geomagnetism, Kyoto University, Japan (http://wdc.kugi.kyoto-u.ac.jp). In Table $1 R i$ is the monthly mean of the international relative sunspot number and $A p$ is an averaged planetary geomagnetic index based on data from a set of specific geomagnetic observatories. The daily $A p$ index serves to classify the storms as: minor geomagnetic storm when $29<A p<50$; major geomagnetic storm when $49<A p<100$; and severe geomagnetic storm when $A p \geq 100$ (Coffey and Erwin 2001). In addition, international geomagnetically disturbed days (Ddays) and the quietest days (Q-days) are also given in Table 1 together with the UT of the storm sudden commencement (SSC). Criteria used in the rankings the 10 most geomagnetically quiet days of the month from most (Q1) to least quiet (Q10) and the 5 most geomagnetically active days from the most 
(D1) to least disturbed (D5) include the sum of the eight planetary 3-hour range $K p$ index values, the sum of the squares of the eight $K p$ values, and the greatest $K p$ value (http://www.iugg.org/IAGA). Thus, the five disturbed and the ten quiet days of each month could define the extremes of day-to-day ionospheric variability if the geomagnetic activity were the only source of this variability (Mendillo 2006). Days without numbers in brackets (Table 1), that are neither geomagnetically quiet nor disturbed, point also to the role of other solar-terrestrial processes involved in the complex ionosphere structure and dynamic.

\section{F REGION STORM MORPHOLOGY AT CHILTON IONOSONDE STATION}

Realistic simulations of both positive and negative disturbance deviations from the average monthly median behaviour following a storm commencement require detailed descriptions of the storm morphology. In this paper a proper examination how the spatio-temporal storm patterns develop and how they are related to solar and geomagnetic activity (Table 1) for the characteristic descriptive of $\mathrm{F}$ region ionisation, $f o \mathrm{~F} 2$, has been done by looking at different individual storms.

The hourly daily critical frequency $f_{o} \mathrm{~F} 2$ measurements at Chilton taken during October 1996 are shown grouped together in Fig. 1 indicating 22 and 23 October as days of the significant $f o \mathrm{~F} 2$ departure from the overall narrow monthly scattering pattern. During this month, some $f o \mathrm{~F} 2$ values were not observable from the ground indicating possible ionospheric $G$ conditions (Piggott and Rawer 1972). These can be clearly seen on the last two days in Fig. 2. The median values, $f o \mathrm{~F} 2 \mathrm{med}$, shown in Fig. 2 as black line represent average diurnal behaviour at Chilton ionosonde station and enable the storm developments to be studied. They are frequently used to identify the negative and positive storm phase as $f o \mathrm{~F} 2$ decrease $(-25 \%)$ below and increase $(+25 \%)$ above median values during disturbed conditions in terms of the relative deviation $\Delta f o \mathrm{~F} 2(\%)=100 \times\left(f_{o} \mathrm{~F} 2-f_{o} \mathrm{~F} 2 \mathrm{med}\right) / f_{o} \mathrm{~F} 2 \mathrm{med}$. Although Table 1 indicates no storm sudden commencement (SSC) on geomagnetically disturbed day 22 October 1996 (D2), there is an ionospheric storm with short positive phase followed by a negative phase on 23 October 1996 (D3) lasting more than 1 day (Fig. 2). Here ionospheric $G$ conditions perceptible as missing foF 2 data are associated with the negative storm phase (Smithtro and Sojka 2005). During this storm interval, the $f_{o} \mathrm{~F} 2$ varied from 7.5 to $3.0 \mathrm{MHz}$ at noontime while the sunspot number was around 0.9. It is reasonable to assume that the solar EUV flux does not change much during the 5 days period when solar activity remained low. Therefore, it is evident that even at the extreme solar minimum, hourly daily foF 2 changes during minor geomagnetic storm $\left(\max A_{p}=38\right)$ are significant relative to the monthly 


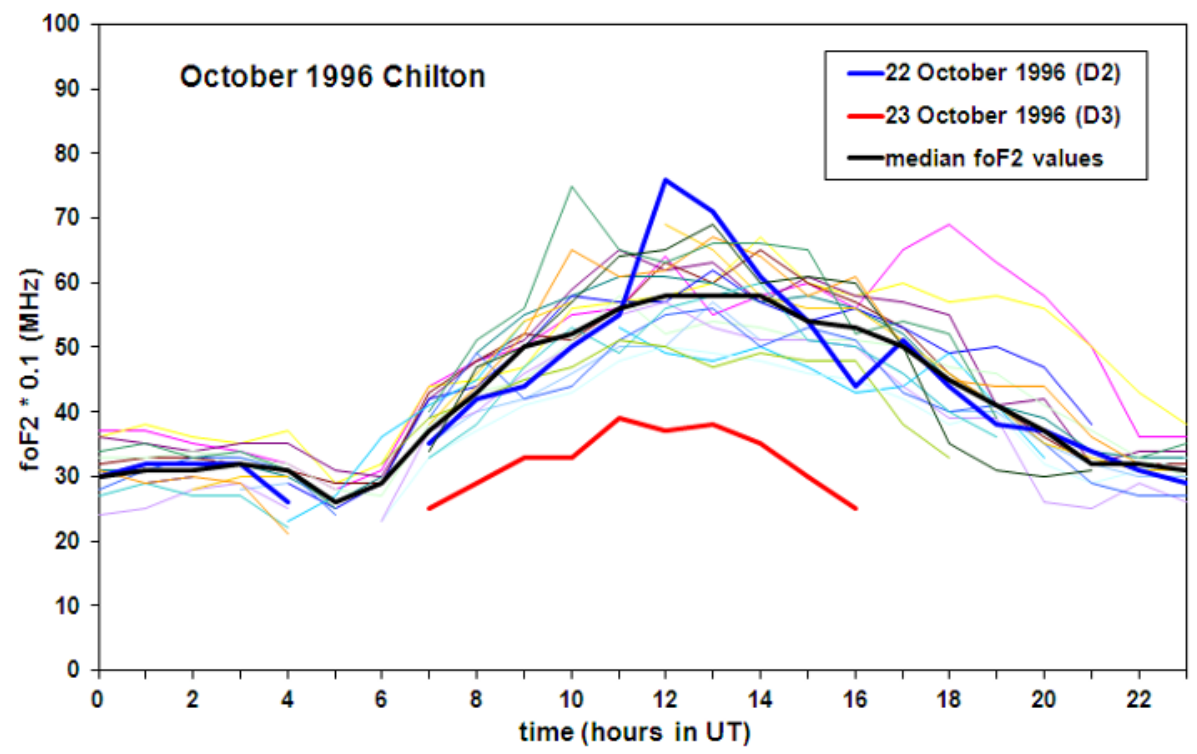

Fig. 1. Time variations of $f_{o} \mathrm{~F} 2$ at Chilton ionosonde station for each day in October 1996.

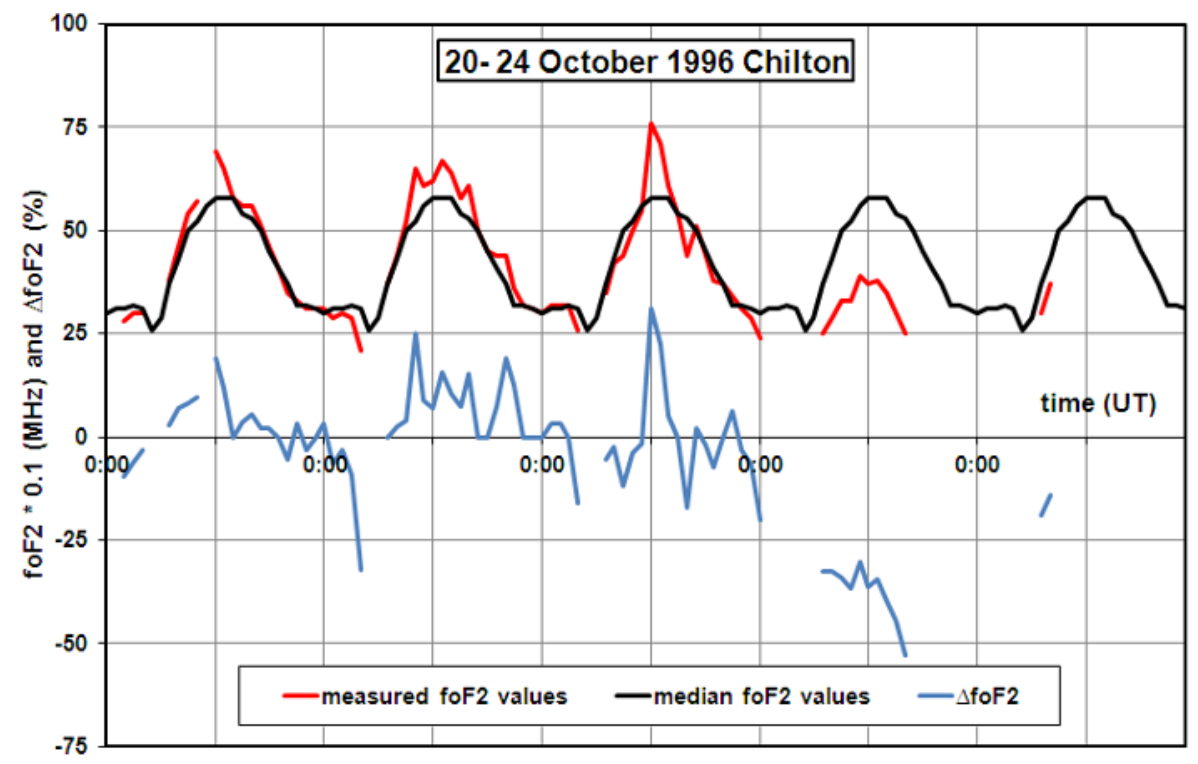

Fig. 2. $f_{o} \mathrm{~F} 2$ measured values with $\Delta f_{o} \mathrm{~F} 2$ between 20 and 24 October 1996 at Chilton ionosonde station. 


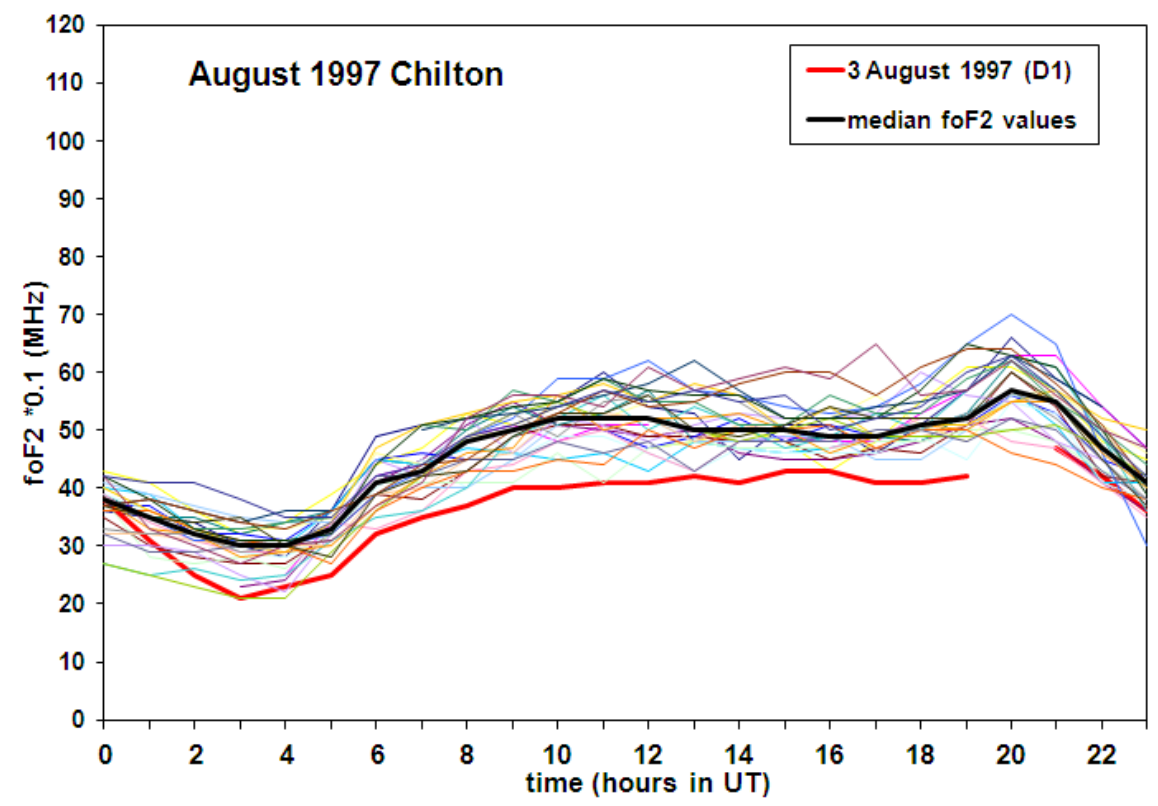

Fig. 3. Time variations of $f o \mathrm{~F} 2$ at Chilton ionosonde station for each day in August 1997.

monthly average behaviour, $\Delta f o \mathrm{~F} 2<-50 \%$. Such behaviour is particularly important in high frequency (HF) radio communication applications (Zolesi and Cander 2014 and references therein).

Results of 31 days of $f o \mathrm{~F} 2$ measurements at Chilton taken during August 1997 and August 2000 are shown grouped together in Fig. 3 and Fig. 4, respectively. They present several interesting phenomena apart from an apparent contrast of solar minimum versus solar maximum diurnal $f_{o} \mathrm{~F} 2$ behavior in the mid-latitude $\mathrm{F}$ region. The diurnal values of $f_{\mathrm{O}} \mathrm{F} 2$ shown in the mass plot of Fig. 3 are significantly lower than those shown in Fig. 4. This is due to the lower solar activity in 1997. Diurnal $f_{o} \mathrm{~F} 2$ values measured in the summer of 2000 were consistently higher than those in the summer of 1997 by a factor of approximately 1.8. This ratio is by far less than the ratio of the mean sunspot number observed during the two summers as 5.3. However, the effect of decreasing solar activity is clear: there are decreases in both the maximum values and the maximum-to-minimum ratio. The late afternoon maximum or the so-called evening anomaly is seen at both figures, though less pronounced at high solar activity. Indeed, monthly median values clearly show an increase in $f o \mathrm{~F} 2$ up to approximately 20:00 UT which indicates that the upper $\mathrm{F}$ region moves downward in the summer afternoon with ionization piling up at the peak of the F2 layer. 


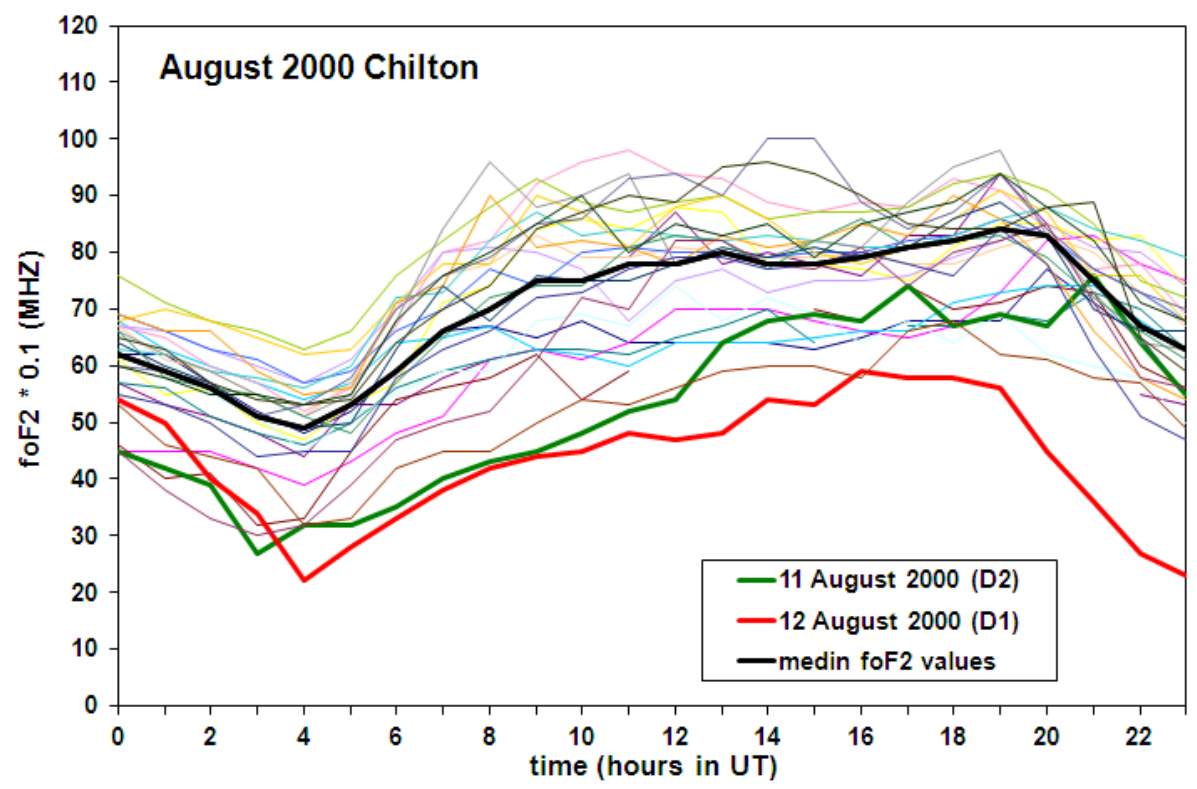

Fig. 4. Time variations of $f o \mathrm{~F} 2$ at Chilton ionosonde station for each day in August 2000 .

From Fig. 5 a strong relation can be seen between the late afternoon maximum value in $f o \mathrm{~F} 2$ and the geomagnetic conditions. Figure 5 shows data from 2 to 6 August 1997. As given in Table 1, three of the ten geomagnetically quietest days (e.g., Q9, Q3, and Q2) and one of the five geomagnetically disturbed days (e.g., D1) of the month occurred during the period. Although it appears that the afternoon maximum in $f o \mathrm{~F} 2$ was higher when the geomagnetic activity was low than when activity was high, the late afternoon maximum value of $f o \mathrm{~F} 2$ was not well related to geomagnetic conditions during the 10-14 August 2000 disturbed period (Fig. 6).

However, the most dominant feature of the mass plots in Figs. 1, 3, and 4 is a large day-to-day scatter in the $f o \mathrm{~F} 2$ values, confirming striking $\mathrm{F}$ region sensitivity to rapidly changing solar-terrestrial activity. There are many scatters due to the geomagnetic storm that is found to be a permanent feature of all events here examined. It is also evident that all storms in 1996 and 1997 are small-scale geomagnetic disturbances. The 3 August 1997 minor storm affected the upper atmosphere in such a manner that the $f_{o} \mathrm{~F} 2$ variation appeared initially (early afternoon) as a positive-value phase, then was followed by a negative level for the next 36 hours, and finally returned to the median level as shown in Fig. 5. The $f o \mathrm{~F} 2$ median value is here in excellent agreement with the measured $f o \mathrm{~F} 2$ on the geomagnetically quiet (Q2) $6 \mathrm{Au}-$ 


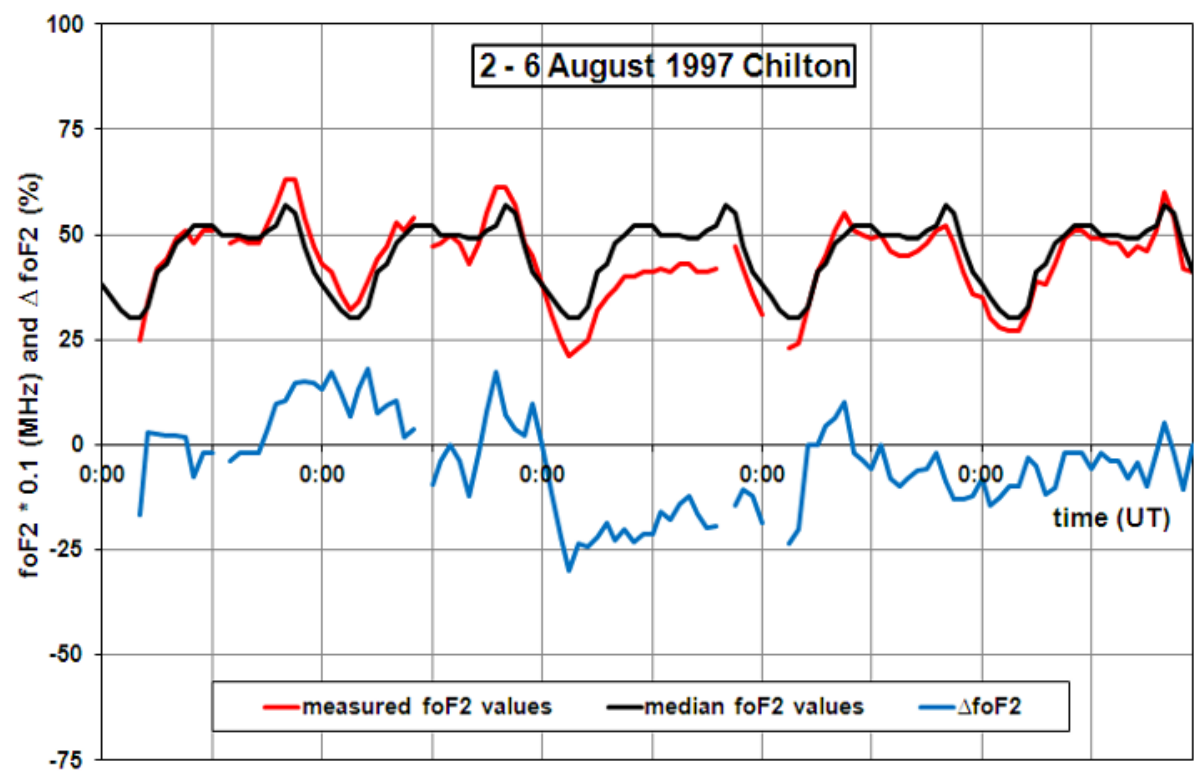

Fig. 5. $f o \mathrm{~F} 2$ measured values with $\Delta f o \mathrm{~F} 2$ between 2 and 6 August 1997 at Chilton ionosonde station.

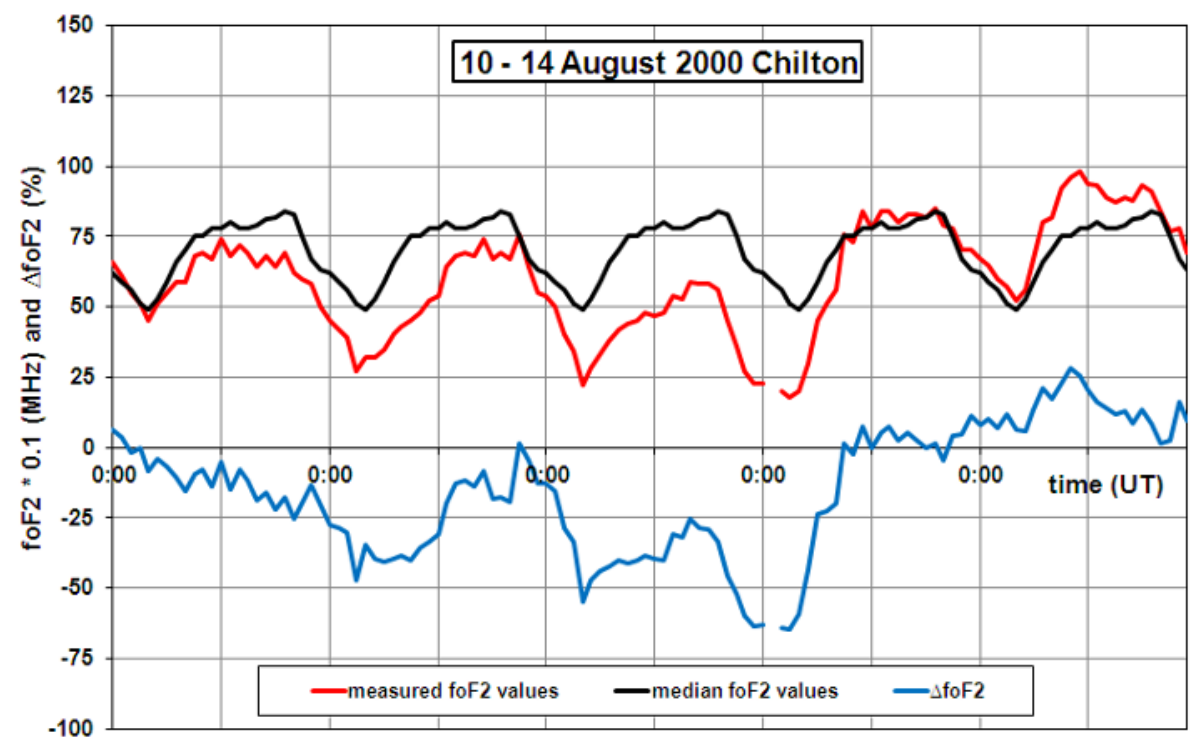

Fig. 6. $f o \mathrm{~F} 2$ measured values with $\Delta f o \mathrm{~F} 2$ between 10 and 14 August 2000 at Chilton ionosonde station. 
gust. The measured $f o \mathrm{~F} 2$ values in Fig. 5 illustrate the capability of the F region to recover quickly after a minor storm, where the magnitudes of $\Delta f o \mathrm{~F} 2$ scarcely crossed the storm threshold level of $\pm 25 \%$. This pattern was not repeated during the severe storm of 11 August 2000 illustrated in Fig. 6. In contrast to Fig. 5, the $\mathrm{F}$ region storm pattern exhibits only negative phase in $f o \mathrm{~F} 2$ with the large depletions in measured $f o \mathrm{~F} 2$ values during both daytime (around $-40 \%$ ) and night-time (around $-60 \%$ ) ionosphere and the long lasting disturbed ionospheric structure. Such behaviour puts great limitation not only on proper understanding of the underlying sources of ionospheric storm during summer season but its forecasting too. This difference is emblematic of the difficulty of bringing the forecast $f o \mathrm{~F} 2$ values into agreement with the measurements.

The beginning and end of February 1997 was a period of low solar activity $(R i=7.6)$ and moderate geomagnetic activity $(\max A p=37)$. The severity of the F region disturbances was indicated in Fig. 7 by positive $f o F 2$ deviations from median on 8 and 26 February. Accompanying with the minor geomagnetic disturbance on 8 February 1997 at 09:54 UT, the foF2 values strongly and suddenly increased with about 55\% (Fig. 8a). The levels of the positive perturbed $f o \mathrm{~F} 2$ values also grow longer at daytime on 9 and 11 February, which was caused by additional SSCs at 13:22 and 04:58 UT,

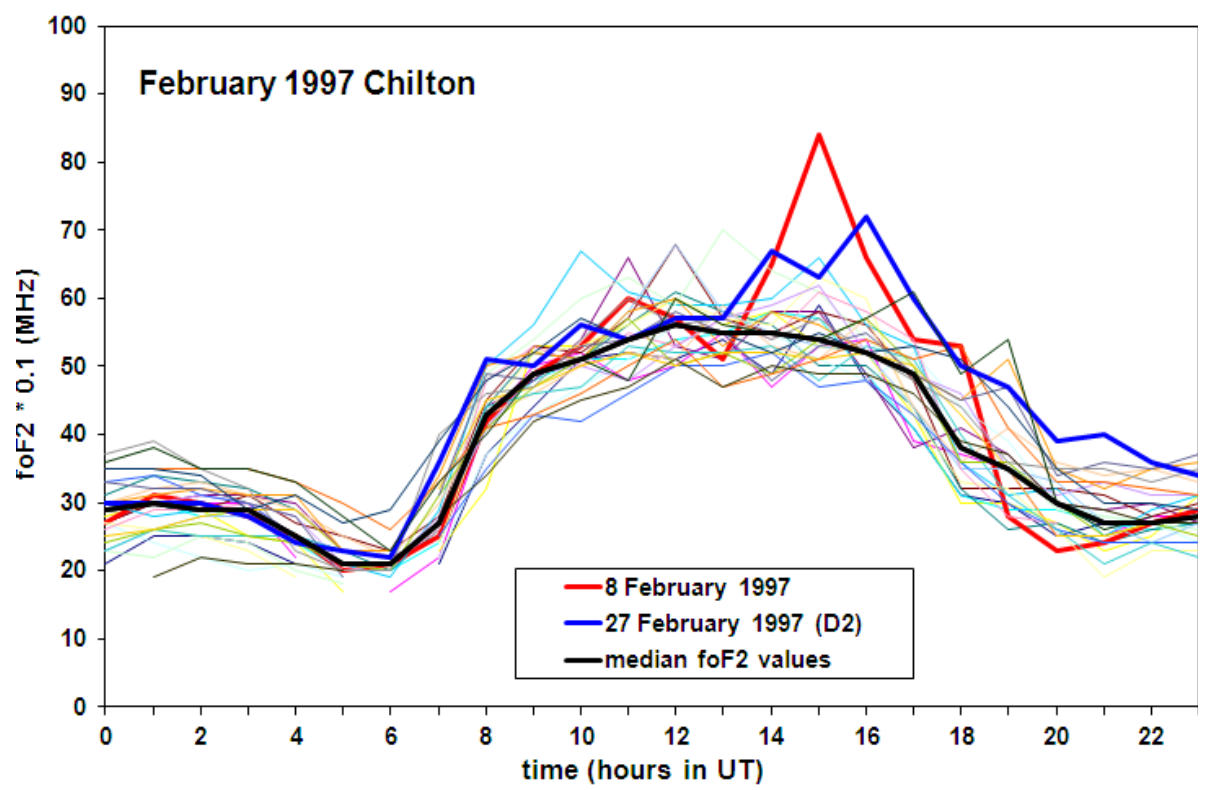

Fig. 7. Time variations of $f o \mathrm{~F} 2$ at Chilton ionosonde station for each day in February 1997. 


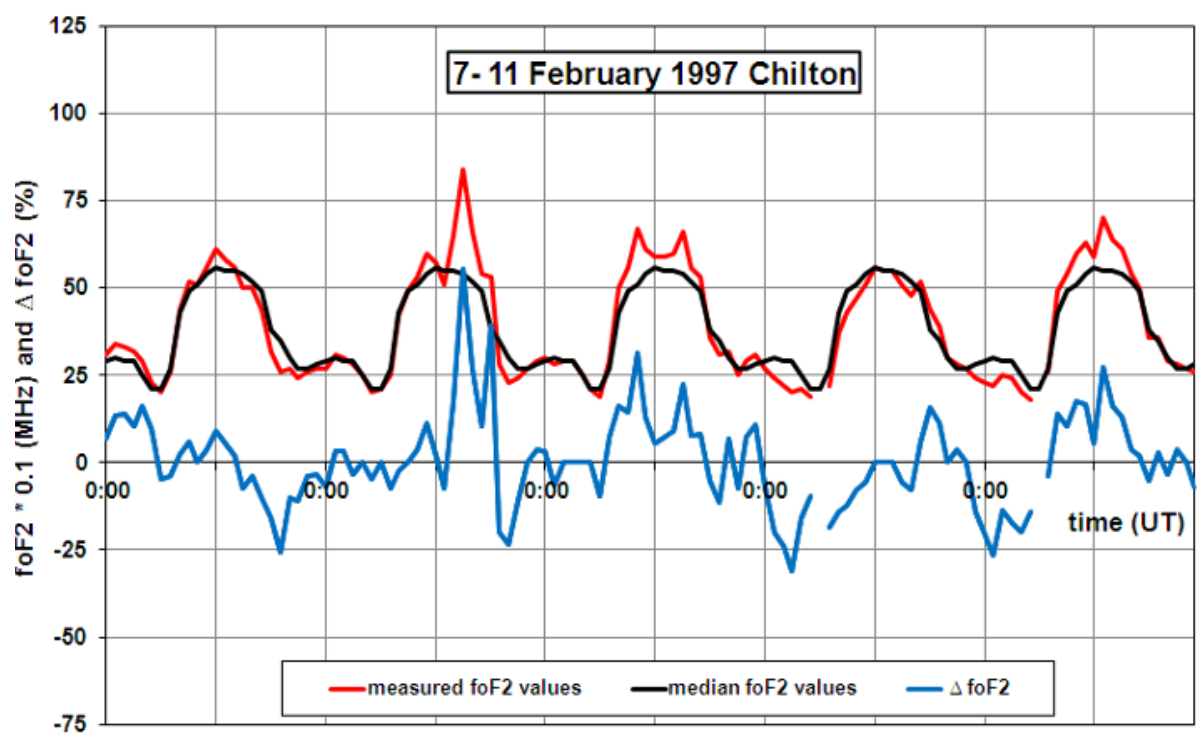

Fig. 8a. foF 2 measured values with $\Delta f o \mathrm{~F} 2$ between 7 and 11 February 1997 at Chilton ionosonde station.

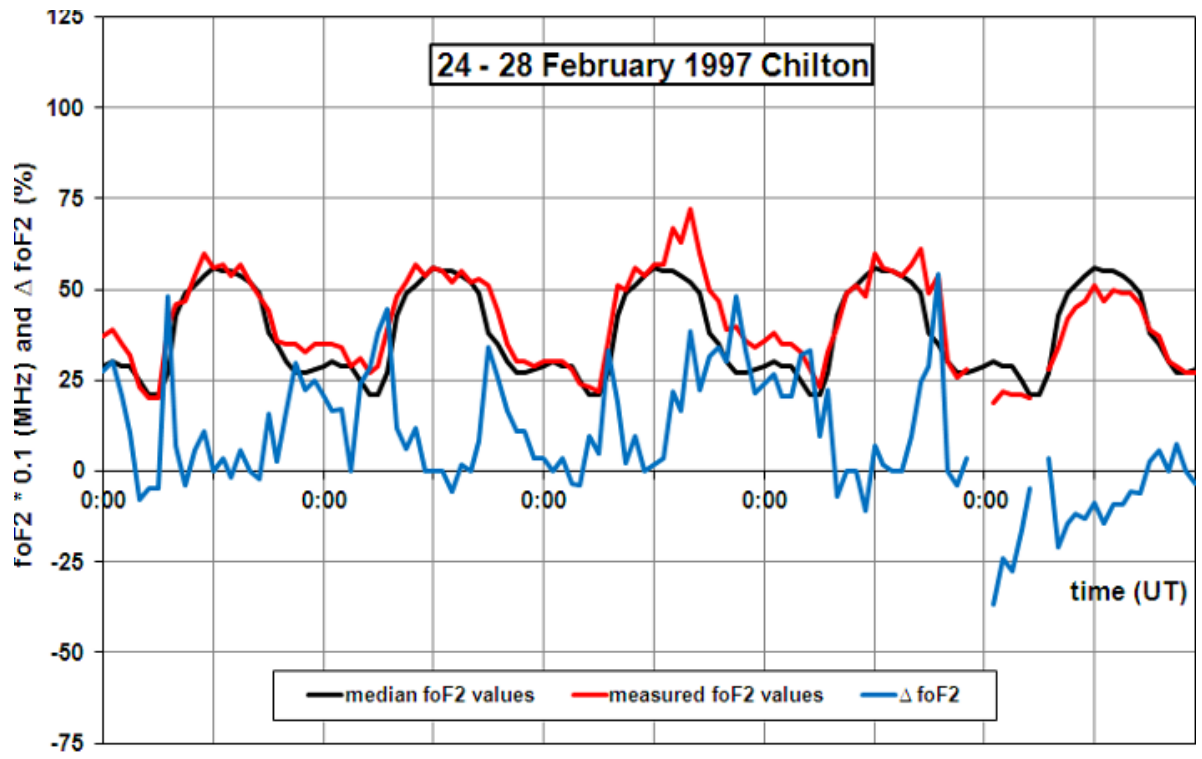

Fig. 8b. foF 2 measured values with $\Delta f o \mathrm{~F} 2$ between 24 and 28 February 1997 at Chilton ionosonde station. 


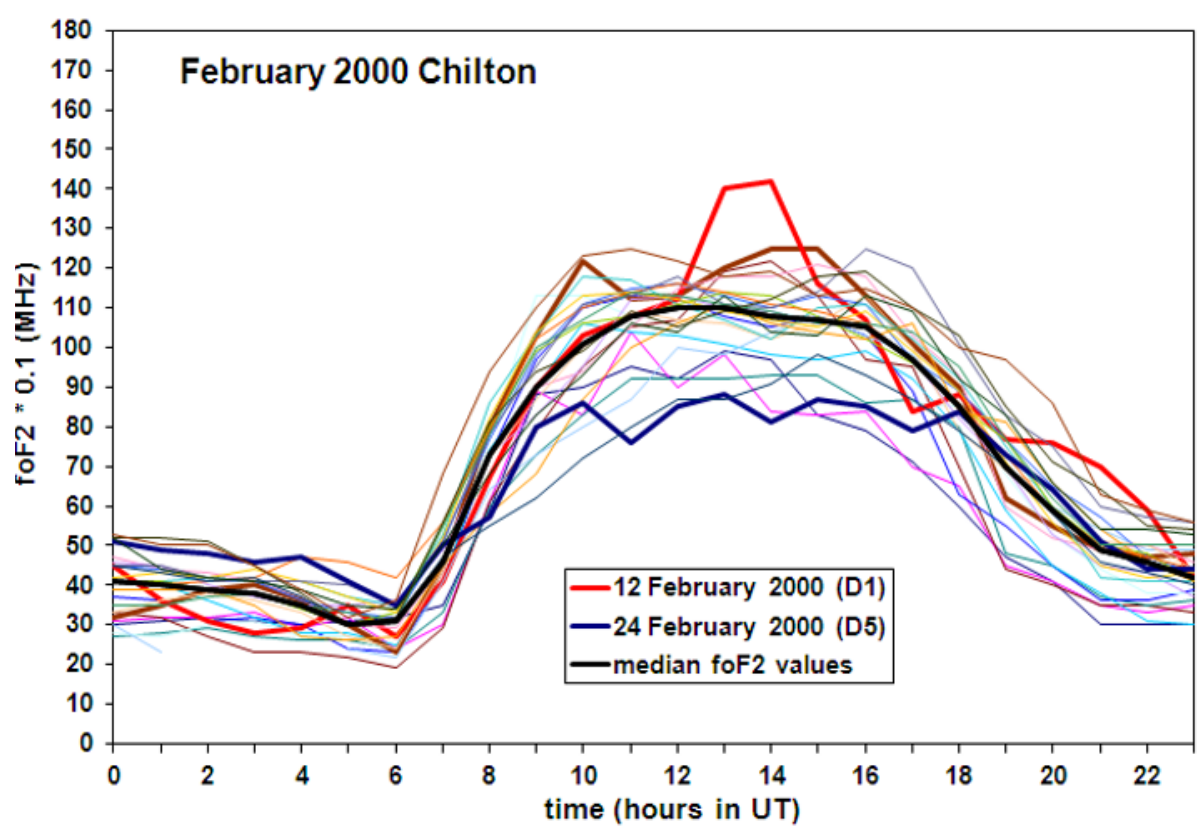

Fig. 9. Time variations of $f o \mathrm{~F} 2$ at Chilton ionosonde station for each day in February 2000 .

respectively (Table 1 ). As is also seen in Fig. 8 b, the level of the $f o \mathrm{~F} 2$ variations tends to increase during the first day of the minor storm of 26 February 1997 and then oscillate to the usual day level in a few days after the beginning of the storm. In addition, an interesting influence of the Travelling Ionospheric Disturbances (TIDs) is visible in $f o \mathrm{~F} 2$ oscillations on 26 and 27 February 1997 (Dominici et al. 1988, Hocke and Schlegel 1996, Afraimovich et al. 2001).

The scatter in data plotted at Fig. 9 for each day in February 2000 shows that the measured $f_{o} \mathrm{~F} 2$ values were far from close to average, as represented by the monthly median, on a number of days following two storm periods. The major storm of 11 February 2000 (Fig. 10a) affected the foF2 variation with daytime enhancements on the first and second days, negative phase during the night-time and speedy recovery later on. During the second storm in February 2000, the enhancement starts after the storm onset and produces clear but relatively small positive phase (Fig. 10b). A negative phase occurs on the second day and lasts more than 24 hours. However, having in mind the high solar $(R i=112.9)$ as well as geomagnetic activity in February 2000 $(\max A p=60)$ it should be noted that the $f o \mathrm{~F} 2$ modification was comparatively small during disturbed times. Consequently, it seems that minor storms 


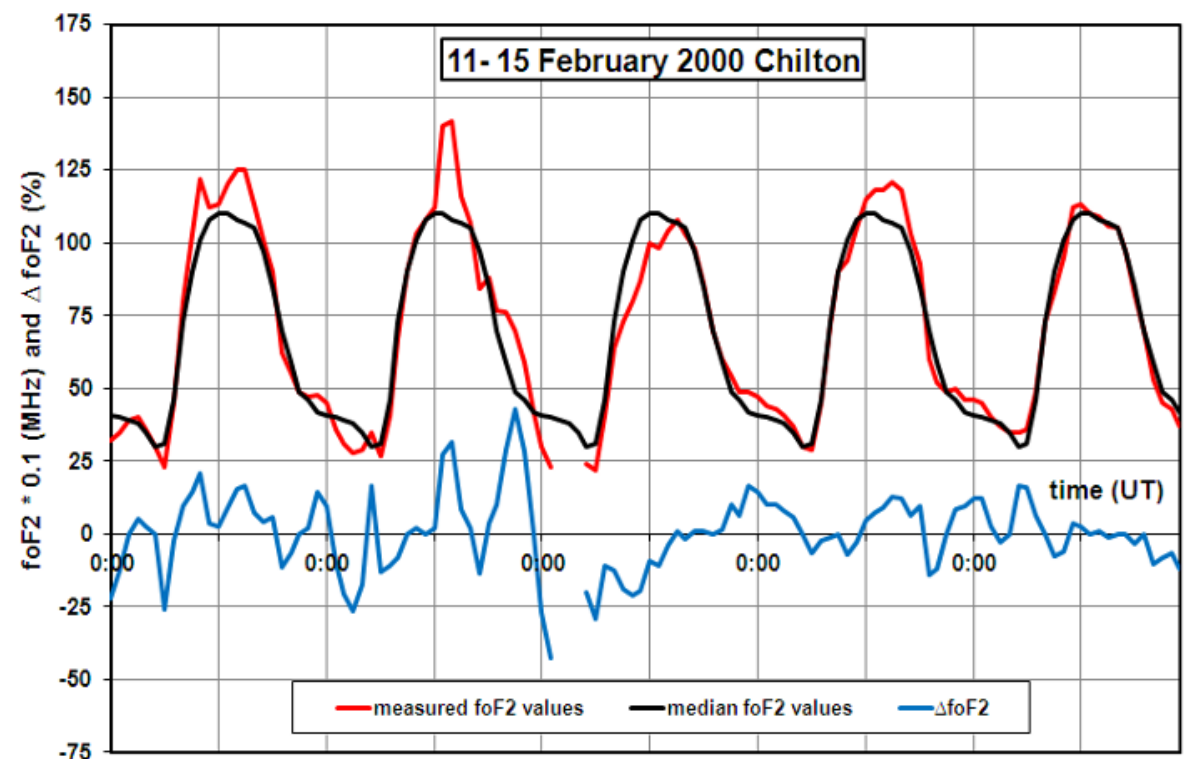

Fig. 10a. $f_{o \mathrm{~F}} 2$ measured values with $\Delta f o \mathrm{~F} 2$ between 11 and 15 February 2000 at Chilton ionosonde station.

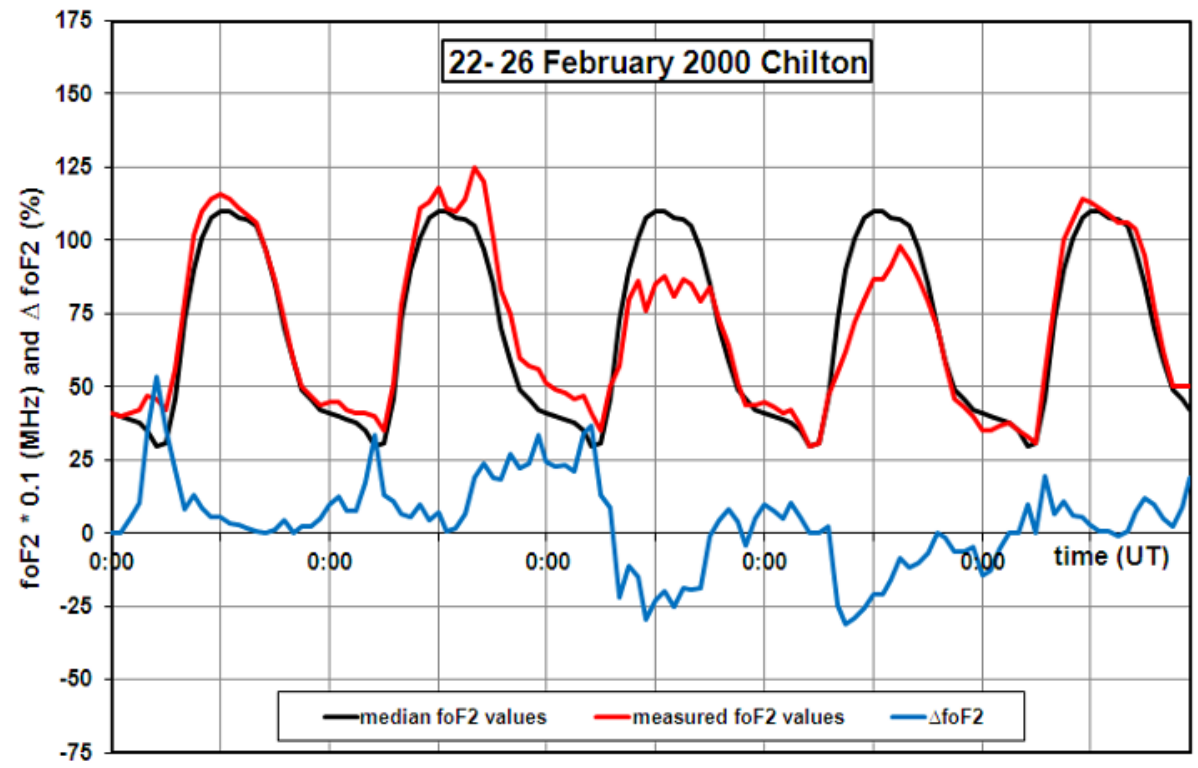

Fig. 10b. foF 2 measured values with $\Delta f o \mathrm{~F} 2$ between 22 and 26 February 2000 at Chilton ionosonde station. 


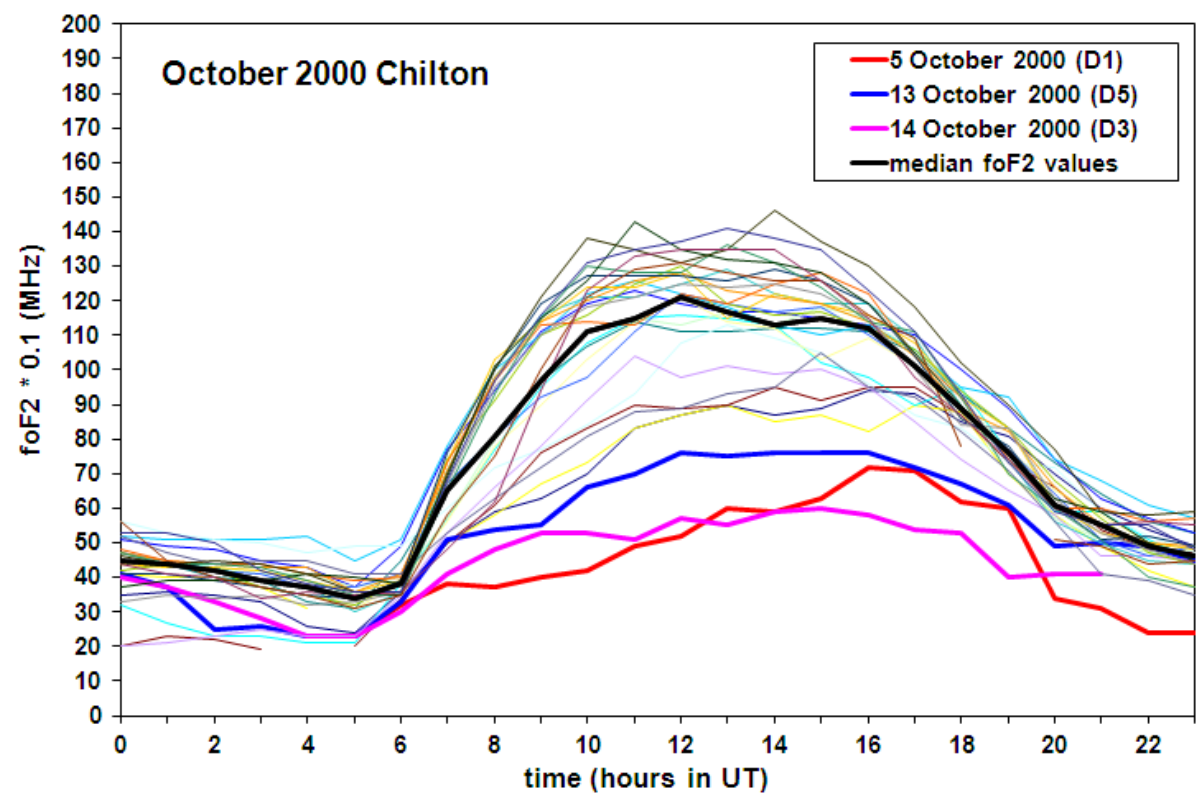

Fig. 11. Time variations of $f o \mathrm{~F} 2$ at Chilton ionosonde station for each day in October 2000.

in February at low level of solar activity (Figs. 8a and b) produced similar if not stronger effect than major storms in February at high level of solar activity (Figs. 10a and b). This important finding neither can be easily explained nor accurately forecast with existing knowledge.

All this certainly was not the case in October 2000, where the scatter $f_{o} \mathrm{~F} 2$ measurements for 31 days at Chilton ionosonde station are shown grouped together in Fig. 11. The large scatter at any fixed UT again emphasises significant day-to-day variability. Although there is considerable scatter above the monthly median, the figure shows a clear tendency for negative storm effects. This is well illustrated in Figs. 12a and b where details concerning two storms from Table 1 are given. Both ionospheric storms show no positive phase at any stage of development. The most severe depletions (about -40 to $-60 \%$ ) occur in the daytime sectors but persist into the night-side too. One of the most interesting findings that has profound consequence on storm forecasting is the changes in $f o \mathrm{~F} 2$ from quiet to disturbed times on 2 and $12 \mathrm{Oc}$ tober when measured $f_{o} \mathrm{~F} 2$ decreases more quickly than increases during the long lasting recovery phase on 6 and 15 October, respectively.

Although most results confirm the very well known fact that a seasonal variation of the positive and negative phases in $f o \mathrm{~F} 2$ exists when storm effects are compared for winter (Figs. 7 and 9) and summer (Figs. 3 and 4) it is 


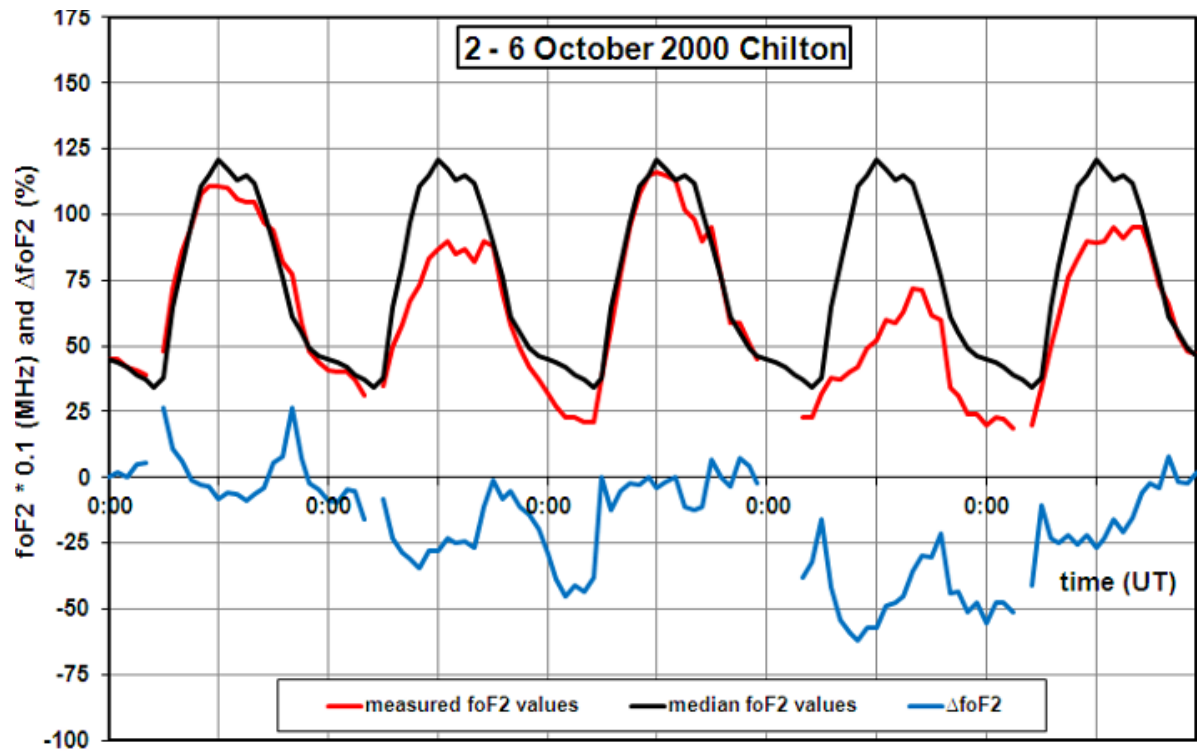

Fig. 12a. $f_{o F} 2$ measured values with $\Delta f o \mathrm{~F} 2$ between 2 and 6 October 2000 at Chilton ionosonde station.

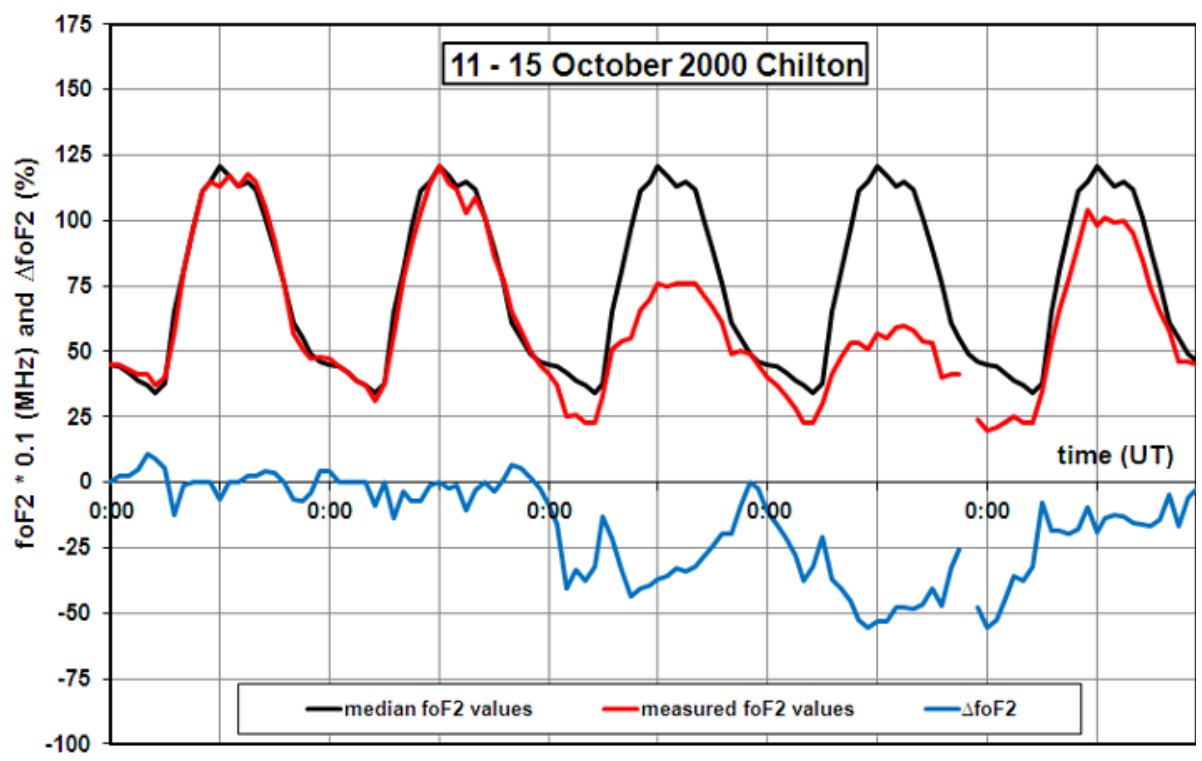

Fig. 12b. foF 2 measured values with $\Delta f o \mathrm{~F} 2$ between 11 and 15 October 2000 at Chilton ionosonde station. 


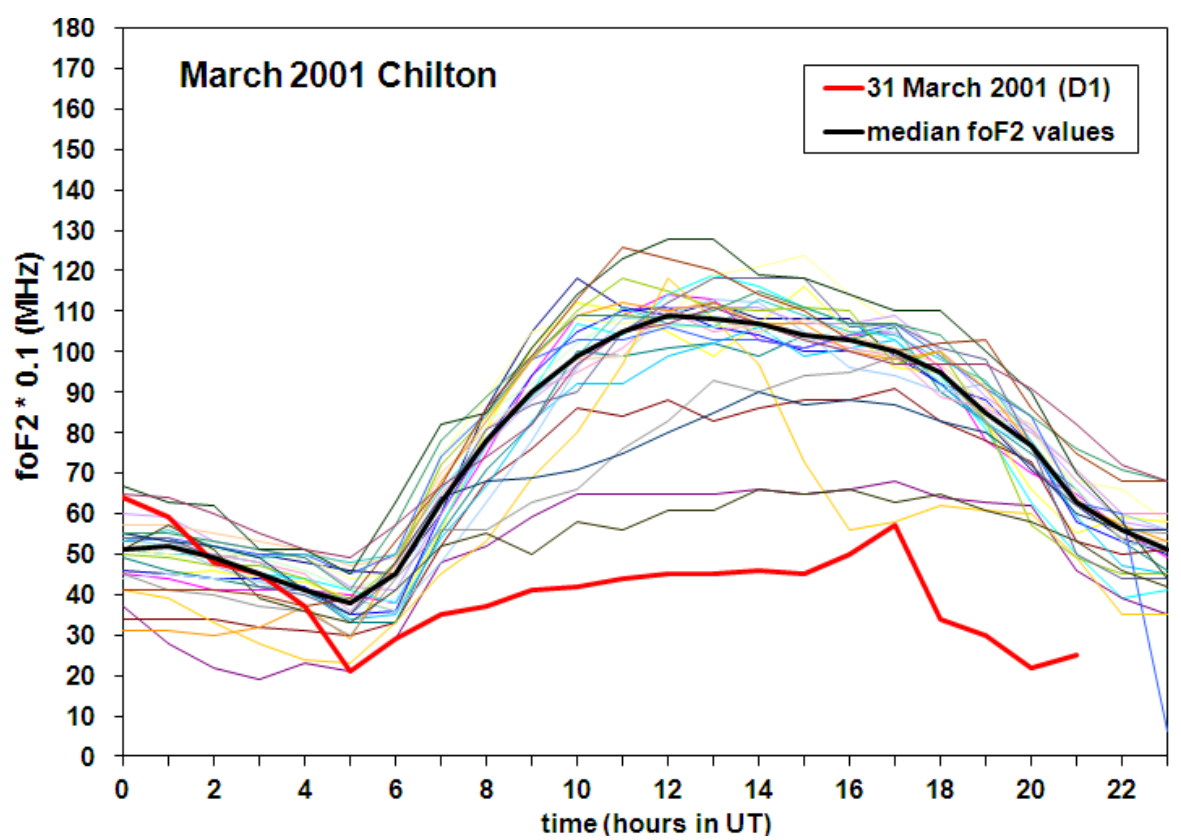

Fig. 13. Time variations of $f o \mathrm{~F} 2$ at Chilton ionosonde station for each day in March 2001.

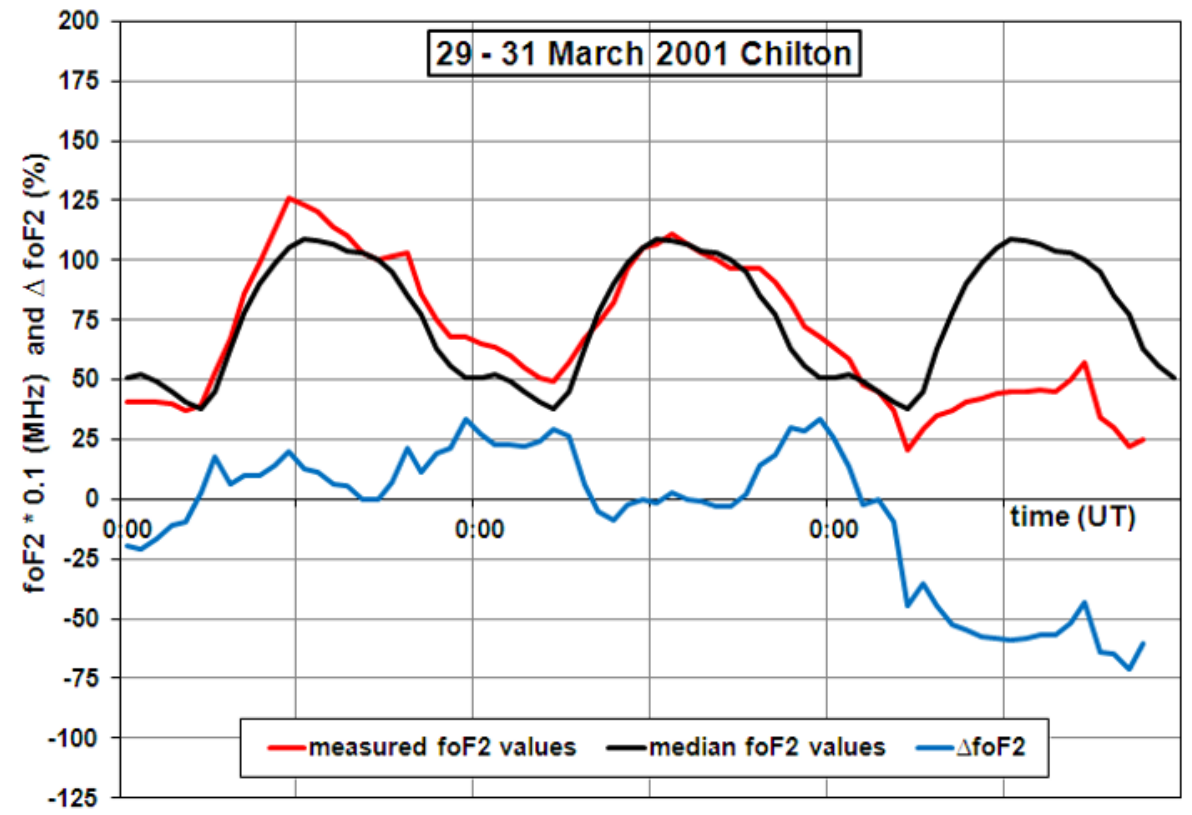

Fig. 14. foF 2 measured values with $\Delta f o \mathrm{~F} 2$ between 29 and 31 March 2001 at Chilton ionosonde station. 
evident that the storm pattern is much more complex. We argued that foF 2 enhancements at Chilton winter ionospheric storm patterns are not to be strongly dependent neither on geomagnetic nor solar activity levels. While varying in magnitude, depletions in $f o \mathrm{~F} 2$ are generally more severe in summer and equinox storm patterns. Furthermore, all the results show that daytime $f o \mathrm{~F} 2$ is greater in winter (Fig. 9) than in summer by day (Fig. 4) which is a clear demonstration of the winter or seasonal anomaly (Rishbeth et al. 2000). The semi-annual anomaly can be also seen in Figs. 11 and 4 when $f_{o} \mathrm{~F} 2$ is greater at equinox than at summer. It has been emphasised by Millward et al. (1996) that the changes in chemical composition, specifically $\left[\mathrm{O} / \mathrm{N}_{2}\right]$ ratio, taken in conjunction with the seasonal changes of solar zenith angle are responsible for the existence of both seasonal and semi-annual anomaly behaviour of $f o \mathrm{~F} 2$.

Changes in daily hourly $f_{o} \mathrm{~F} 2$ values for all the March 2001 data are shown in Fig. 13. Evidently there is a part of scatter in Fig. 13 that can be attributed to the high level of geomagnetic activity (Table 1). As in previous figures, black and red solid lines represent median and storm day $f o \mathrm{~F} 2$ variations, respectively. Once more during daytime the variability in $f o \mathrm{~F} 2$ is found to be considerably larger than by night-time. Both Figs. 13 and 14 displays the last day of March 2001 being the most disturbed period of the month with very well define negative phase in $f o \mathrm{~F} 2$. The negative phase of the ionospheric storm is detected in early morning hours (after 05:00 UT) of 31 March with the severe depletions of more than $-60 \%$ relative to the median $f o \mathrm{~F} 2$ values. Accordingly, it is clear that disturbed ionisation structure during geomagnetic storms creates a large number of different technical, scientific and numerical problems in matching the rapid $f_{o} \mathrm{~F} 2$ variations in measured data with corresponding forecasting model's outputs as storms develop. The factors that lead to such a complex $F$ region behaviour even at a single ionosonde station of Chilton are beyond the scope of this paper.

\section{F REGION STORM FORECASTING}

There are number of ionospheric global and regional prediction models based on an empirical fit to hourly monthly median values extracted from an archived ionosonde data base for past solar cycles (Bradley 1995, Hanbaba 1999 and references therein). These climatological models are often used, among other purposes, to provide very important quiet-day reference for the world-wide ionospheric conditions. Critical to this type of modelling is the formulation of maps giving the geographical variations of individual model parameters. Reference global maps in current international use are those recommended by International Telecommunication Union (ITU). Important element in these long-term models is a statistical indication of the ionospheric day-to-day variability that is parameterised by the decile factors in 
ITU-R approach (ITU-R 1997). Currently the best known ionospheric model is the IRI-International Reference Ionosphere (Bilitza et al. 2011). It provides monthly averages of ionospheric electron density, plasma temperature, and ion composition as a function of altitude for any location and time. More recently the ionospheric day-to-day variability is incorporated into IRI model (Fuller-Rowell et al. 2000b, Huang et al. 2001).

The same is the case with European regional ionospheric monthly median models developed under the four ionospheric COST (European Cooperation in the field of Scientific and Technical Research) Actions over the period 1999-2008 and currently available for implementation in different applications (Zolesi and Cander 2014 and references therein). It is important to note that within these Actions related to the effects of the upper atmosphere on terrestrial and Earth-space communications, studies have been conducted aiming to produce statistically derived expressions indicative of departures from ionospheric median values as a function of different conditions including time of day, season, and extreme solar-terrestrial activity (Strangeways et al. 2009). Considerable progress has been made in developing techniques which permit the updating of $F$ region monthly median prediction using either single-station ionospheric data or an effective sunspot number or both (Reilly et al. 1991, Wilkinson et al. 2001, Pezzopane et al. 2011, 2013). An empirical storm-term correction model has been developed by Fuller-Rowell et al. (2000b) to predict the departure of $f o \mathrm{~F} 2$ from the monthly median or a quiet-time reference model during a geomagnetic storm. These techniques provide a link and a reference base between the climatological modelling and short-term forecasting. Thus it would be useful to make these techniques internationally available for testing and verification.

Although the $\mathrm{F}$ region forecasting might be applied in terms of deviations from median or average conditions upcoming from the prediction models, the morphological characteristics of individual ionospheric storms, as shown in Section 3, clearly demonstrate that storm forecasting requires different approach. It requires a specification of storm-time ionospheric variability on generally less predictable time-scale such as few hours in advance. This is because the largest contribution to the ionospheric day-to-day variability comes from storm effects and their pattern has to be known. One of the first steps towards forecasting and mapping ionospheric space weather over Europe has been made at the Rutherford Appleton Laboratory, UK, by providing an interactive tool for the Short-Term Ionospheric Forecasting (STIF) over Europe. The forecasts of $f o F 2$, MUF(3000)F2 (Maximum Usable Frequency for $3000 \mathrm{~km}$ distance), TEC and FOT (Frequency of Optimum Traffic) up to 24-hours ahead were available on-line (Dick et al. 1999). Figure 15 shows the measured $f_{o} \mathrm{~F} 2$ at Chilton compared with the 24hours ahead corresponding STIF values for this particular single station 


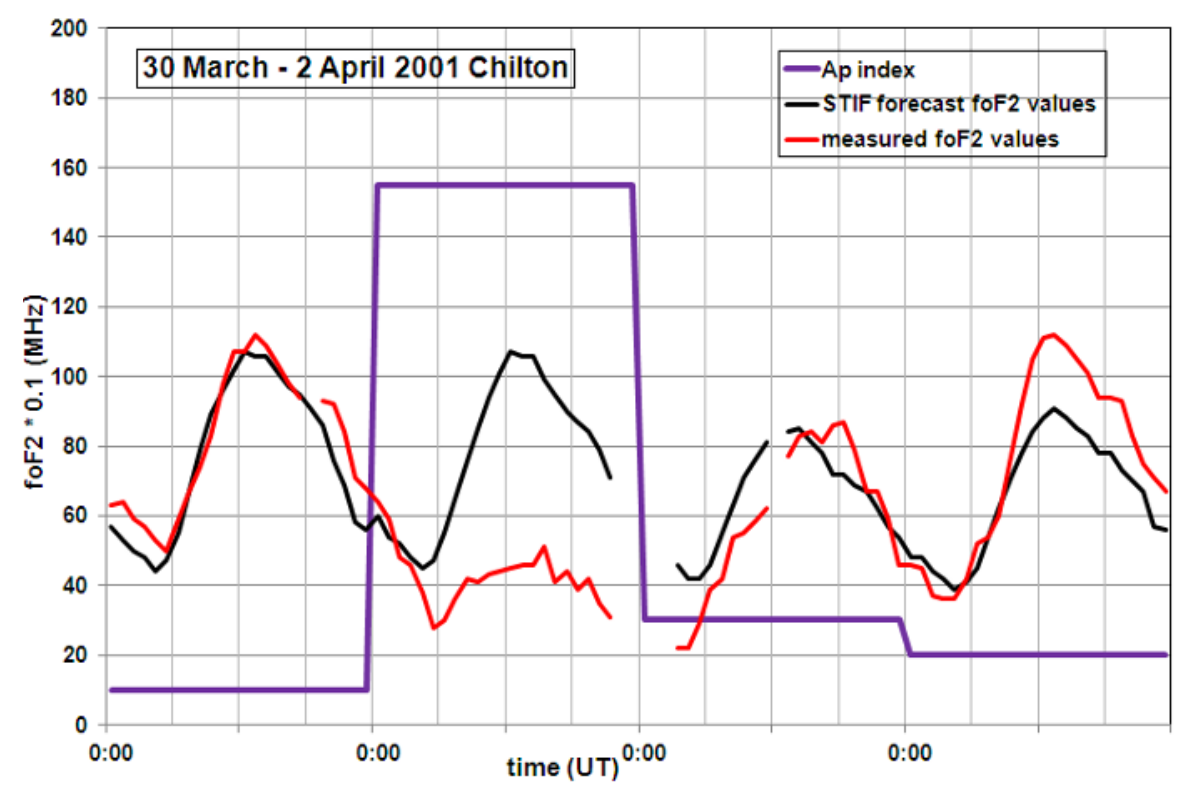

Fig. 15. The STIF 24-hours ahead forecast and measured $f_{o} \mathrm{~F} 2$ values between 30 March and 2 April 2001 at Chilton ionosonde station with $A p$ values as an indicator of high geomagnetic activity level.

over the period 30 March - 2 April 2001. Related geomagnetic conditions are described by daily $A p$ index at the same figure. While $f_{o} \mathrm{~F} 2$ forecast values indicate a little departure from the measured data on 30 March, they show a substantial increase above (31 March) and a slight decrease below ( 2 April) the measured values during the larger event $(A p=155)$ started on early hours of 31 March 2001. This disagreement between the forecast and measured $\mathrm{F}$ region densities at the beginning of the storm period, particularly in the first 24 hours, is a well-known and long-standing ionospheric forecasting problem. It is also closely related to the problem of the geomagnetic storm forecasting evidently present in sudden change of the $A p$ index from $A p=10$ on 30 March to $A p=155$ on 31 March. However, reasonably good agreement between forecast and measured $f_{o} \mathrm{~F} 2$ values just before the storm beginning and on the second storm day seen at Fig. 15 is satisfactory under the conditions of the STIF method's generation and its purpose.

Following this approach, the subsequent STIF forecasting example is shown in Fig. 16. It demonstrates how well the STIF 24-hours ahead forecast agrees with measured $f o \mathrm{~F} 2$ values during the ten quietest days in March 2001 at Chilton ionosonde station. Overall comparisons with observations are encouraging because of the small errors (RMSE $=0.87 \mathrm{MHz}$ and $\mathrm{NRMSE}=0.35$ over 239 measured hourly $f_{o} \mathrm{~F} 2$ values) and a high consis- 


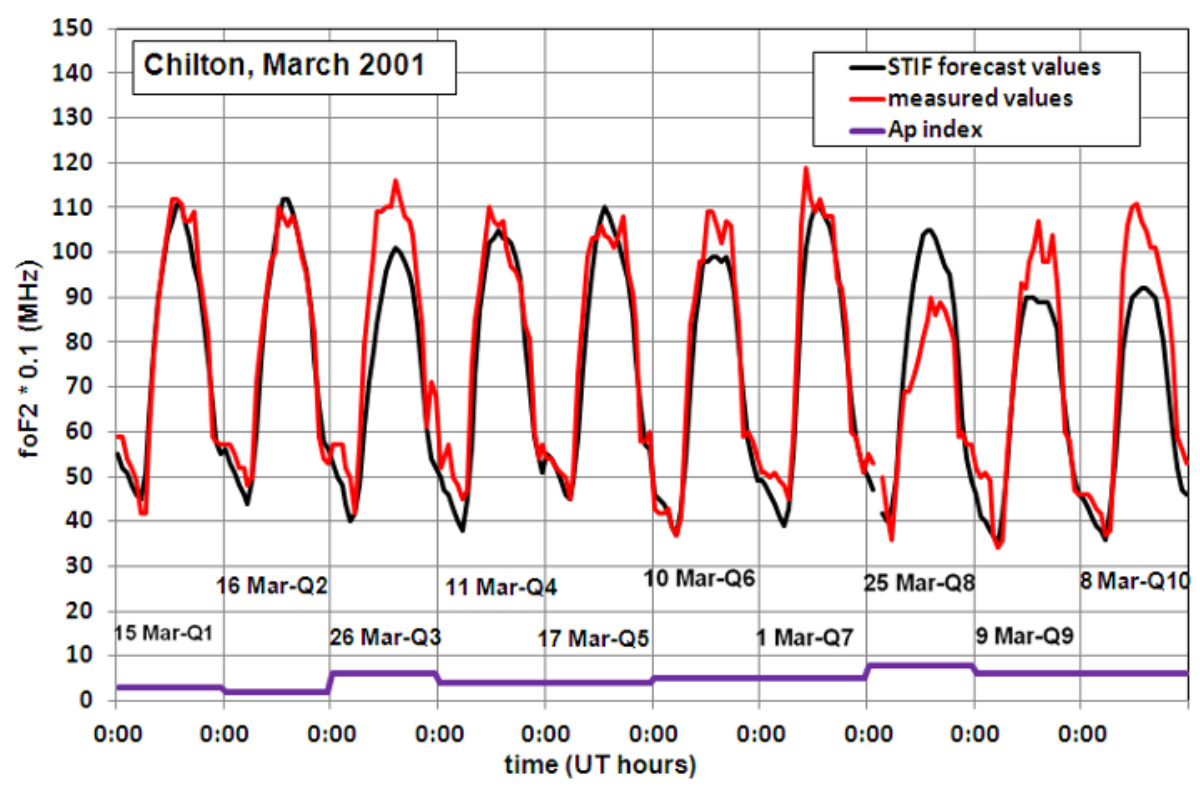

Fig. 16. The STIF 24-hours ahead forecast and measured $f_{o} \mathrm{~F} 2$ values during the ten quietest days (from Q1 to Q10) in March 2001 at Chilton ionosonde station conditions with $A p$ values as an indicator of low geomagnetic activity level.

tence between diurnal morphologies exhibited by the STIF method and the observed trends (Cander et al. 2003). The STIF method does not require neither predicted nor past values of any solar and geomagnetic indices to forecast 24-hour ahead the $f_{o} \mathrm{~F} 2$ values even during geomagnetically very disturbed periods as those in March 2001 at Chilton ionosonde station (Fig. 15). In addition, the STIF method does not require $f o \mathrm{~F} 2$ monthly median values, so that the newly developed sliding median approach (Mukhtarov et al. 2013), although very useful in ionospheric modelling, is not applicable. However, it has to be emphasized that the STIF technique's success is based on a continuos and rapid measurements over as largest area as possible because it requires near real-time data availability in conjunction with mathematical algorithms to extrapolate the ionospheric conditions some time ahead. Thus, the world and/or regional centres for data collection and processing in near-real time should be available making the final products, such as the $\mathrm{F}$ region storm forecasting, useful and promptly available for the different users.

\section{CONCLUSIONS}

Modern ground-based and satellite communications networks and systems rely on innovations in the radio frequency (RF) domain and demand a full 
understanding of the underlying details within the different propagation RF aspects under expected conditions (Bilitza 2002). Hence one of the requirements of these cutting-edge technologies and processes partly addressed by this paper is $\mathrm{F}$ region ionospheric storm morphology and its forecasting. The literature on $\mathrm{F}$ region storm morphology is now so extensive that a comprehensive review is practically impossible. Instead, only few special topics closely related to its forecasting have been selected for discussion. There is generally accepted theory that explains the F region morphology during geomagnetic storms in terms of the thermospheric changes in both neutral winds and chemical composition which ultimately result in changes of the rates of ionisation production and loss. In addition, changes of the electric field and current systems make ionospheric storm morphology yet more complicated. See Prölss (1995), Rishbeth et al. (2000), and Namgaladze et al. (2000) as well as references mentioned therein for reviews of these approaches. In spite of that consensus over physical processes involved in main causes of the $\mathrm{F}$ region storm morphology, the forecasting ability in case of an individual storm is rather limited at the very best (Pietrella 2012). Established by careful examination of Fig. 15 and Fig. 16, it is clear that the STIF method provides acceptable forecast a few hours in advance just before the beginning of the storm, unsatisfactory forecast during the main phase and the right choices of $f o \mathrm{~F} 2$ values 24-hours in advance during the recovery phase as well as during geomagnetically quiet days.

As studies continue to search for the actual physical mechanisms that explain the spatial and temporal morphologies over various space weather conditions and to test forecasting algorithms for practical applications, it would be useful to have well defined patterns of mid-latitude storm $F$ region and a technique to forecast it. A contribution in that direction is given by findings in Section 3 of this paper. It demonstrates that the whole issue of the forecasting techniques of space weather related events in the Earth's ionosphere cannot be a replacement for the solar-terrestrial physic studies where the highly sophisticated equipment is employed to investigate space and Earth phenomena and where models and methods of prediction and forecasting require powerful computers and long-lasting calculations of the high accuracy. To the contrary, ionospheric space weather is a dynamic system dealing with data in near-real time and predicting tools to alert users on major effects which can damage their technological or financial systems. However, many existing ionosondes are not good enough for these purposes. They are not homogeneously distributed around the world and most of them do not provide data in near-real time. In fact most of them are not technical capable to do that. Fortunately, for quite some time, the ionospheric community has been aware of the fact that the International Global Positioning System (GPS) Service for Geodynamics (IGS) with a global ground-based station 
network offers a new multi-point opportunity to observe directly the terrestrial ionosphere and use that information in prediction and forecasting purposes. The total electron content (TEC) evaluated from Global Navigation Satellite System (GNSS) is convenient because: (a) RINEX files for TEC evaluations are available through IGS properly organised at the international level, which means a readily accessible data; (b) RINEX files allow the TEC evaluation with high resolution ( $1 \mathrm{~s}, 30 \mathrm{~s}, 1 \mathrm{~min}, 10 \mathrm{~min}$, and so on), which means a continuous coverage in time with high temporal resolution; and (c) the number of GPS receiver sites is growing every day, which means the simultaneous global coverage. So what is the problem, then? The problem is the technique for TEC data evaluation from GPS measurements. In case of the ionosonde data there is an internationally agreed procedure for data evaluation from ionograms by Piggott and Rawer (1972). On the other hand, in spite of a lot of work, it is not the case with the GNSS TEC values. Does it mean that there is no way anyone can evaluate TEC from GPS or any other GNSS in an exact way? Still whatever technique is used for the TEC evaluation, a large amount of data available in near real-time is a unique opportunity to be used in space weather issues and statistical studies (Fuller-Rowell et al. 2006, Jakowski et al. 2011).

With the service for solar monitoring (e.g., http://sidc.oma.be) already available, the multi-point observing capabilities of GNSS, and shared international real-time ionosonde data resources as these via, e.g., GIRO (Galkin et al. 2012) and DIAS (Cander 2006), the appearance of an effective operational Short-Term Ionospheric Storm Forecasting (STISF) tool to replace existing STIF technique for the global and/or regional interactive use on the World Wide Web is only a matter of time. However, the F region storm morphology and its patterns should still be subject to further investigations.

Acknowledgments. The author thanks J.G. Hickford for his contributions and gratefully acknowledges the reviewers for their most valuable comments and suggestions.

\section{References}

Afraimovich, E.L., E.A. Kosogorov, O.S. Lesyuta, I.I. Ushakov, and A.F. Yakovets (2001), Geomagnetic control of the spectrum of travelling ionospheric disturbances based on data from a global GPS network, Ann. Geophys. 19, 7, 723-731, DOI: 10.5194/angeo-19-723-2001.

Basu, S., S. Basu, K.M. Groves, H.-C. Yeh, S.-Y. Su, F.J. Rich, P.J. Sultan, and M.J. Keskinen (2001), Response of the equatorial ionosphere in the South 
Atlantic region to the great magnetic storm of July 15, 2000, Geophys. Res. Lett. 28, 18, 3577-3580, DOI: 10.1029/2001GL013259.

Bilitza, D. (2001), International Reference Ionosphere 2000, Radio Sci. 36, 2, 261 275, DOI: $10.1029 / 2000$ RS002432.

Bilitza, D. (2002), Ionospheric models for radio propagation studies. In: W.R. Stone (ed.), The Review of Radio Science 1999-2002: Advances in 3G Mobile Communications, Cryptography and Computer Security, EMC for Integrated Circuits, Remote Sensing, Radio Astronomy and More, IEEE Press, Piscataway, 625-680.

Bilitza, D., L.A. McKinnell, B. Reinisch, and T. Fuller-Rowell (2011), The international reference ionosphere today and in the future, J. Geod. 85, 12, 909920, DOI: 10.1007/s00190-010-0427-x.

Bradley, P.A. (1995), PRIME (Prediction Regional Ionospheric Modelling over Europe), COST Action, Vol. 238, Final Report, Commission of the European Communities, Brussels.

Buonsanto, M.J. (1999), Ionospheric storms - A review, Space Sci. Rev. 88, 3, 563 601, DOI: 10.1023/A:1005107532631.

Cander, Lj.R. (2003), Toward forecasting and mapping ionospheric space weather under the COST actions, Adv. Space Res. 31, 4, 957-964, DOI: 10.1016/ S0273-1177(02)00793-7.

Cander, Lj.R. (2006), Why bother with ionospheric prediction and forecasting? In: Manual. European Digital Upper Atmosphere Server, DIAS, 40-42.

Cander, Lj.R. (2008), Ionospheric research and space weather services, J. Atmos. Sol.-Terr. Phys. 70, 15, 1870-1878, DOI: 10.1016/j.jastp.2008.05.010.

Cander, Lj.R. (2015), Forecasting foF2 and MUF(3000)F2 ionospheric characteristics - A challenging space weather frontier, Adv. Space Res. 56, 9,19731981, DOI: 10.1016/j.asr.2015.06.013.

Cander, Lj.R., and S.J. Mihajlovic (2005), Ionospheric spatial and temporal variations during the 29-31 October 2003 storm, J. Atmos. Sol.-Terr. Phys. 67, 12, 1118-1128, DOI: 10.1016/j.jastp.2005.02.020.

Cander, Lj.R., R. Bamford, and J.G. Hickford (2003), Nowcasting and forecasting the foF2, MUF(3000)F2 and TEC based on empirical models and real-time data. In: Proc. 12th Int. Conf. on Antennas and Propagation, 31 March3 April 2003, Conf. Publ. No. 491, Vol. 1, 139-142, DOI: 10.1049/ cp:20030035.

Coffey, H.E., and E.H. Erwin (2001), When do the geomagnetic aa and Ap indices disagree? J. Atmos. Sol.-Terr. Phys. 63, 5, 551-556, DOI: 10.1016/S13646826(00)00171-1.

Dick, M.I., M.F. Levy, Lj.R. Cander, I. Kutiev, and P. Muhtarov (1999), Short-term ionospheric forecasting over Europe. In: IEE Nat. Conf. on Antennas and Progation, 31 March - 1 April 1999, York, UK, 105-107, DOI: 10.1049/ cp:19990025.

Dominici, P., B. Zolesi, and Lj.R. Cander (1988), Preliminary results concerning atmospheric gravity waves deduced from $\mathrm{f}_{\mathrm{o}} \mathrm{F}_{2}$ large-scale oscillations, Phys. Scripta 37, 3, 516-522, DOI: 10.1088/0031-8949/37/3/041. 
Eastwood, J.P. (2008), The science of space weather, Philos. Trans. Roy. Soc. A 366, 1884, 4489-4500, DOI: 10.1098/rsta.2008.0161.

Fox, M.W., and L.F. McNamara (1988), Improved world-wide maps of monthly median foF2, J. Atmos. Terr. Phys. 50, 12, 1077-1086, DOI: 10.1016/00219169(88)90096-7.

Fuller-Rowell, T.J., M.V. Codrescu, R.G. Roble, and A.D. Richmond (1997), How does the thermosphere and ionosphere react to a geomagnetic storm? In: B.T. Tsurutani, W.D. Gonzales, Y. Kamide, and J.K. Arballo (eds.), Magnetic Storms, Geophysical Monograph, Vol. 98, AGU, Washington, 203225, DOI: 10.1029/GM098p0203.

Fuller-Rowell, T.J., M.C. Codrescu, and P. Wilkinson (2000a), Quantitative modeling of the ionospheric response to geomagnetic activity, Ann. Geophys. 18, 7, 766-781, DOI: 10.1007/s00585-000-0766-7.

Fuller-Rowell, T.J., E. Araujo-Pradere, and M.V. Codrescu (2000b), An empirical ionospheric storm-time correction model, Adv. Space Res. 25, 1, 139-146, DOI: 10.1016/S0273-1177(99)00911-4.

Fuller-Rowell, T., E. Araujo-Pradere, C. Minter, M. Codrescu, P. Spencer, D. Robertson, and A.R. Jacobsen (2006), US-TEC: A new data assimilation product from the Space Environment Center characterizing the ionospheric total electron content using real-time GPS data, Radio Sci. 41, 6, RS6003, DOI: $10.1029 / 2005 R$ R003393.

Galkin, I.A., B.W. Reinisch, X. Huang, and D. Bilitza (2012), Assimilation of GIRO data into a real-time IRI, Radio Sci. 47, 4, RS0L07, DOI: 10.1029/ 2011 RS004952.

Hanbaba, R. (1999), Improved quality of service in ionospheric telecommunication systems planning and operation, COST Action 251 Final Report, Space Research Centre, Warsaw, Poland.

Hapgood, M.A. (2011), Towards a scientific understanding of the risk from extreme space weather, Adv. Space. Res. 47, 12, 2059-2072, DOI: 10.1016/j.asr. 2010.02.007.

Hocke, K., and K. Schlegel (1996), A review of atmospheric gravity waves and travelling ionospheric disturbances: 1982-1995, Ann. Geophys. 14, 9, 917940, DOI: $10.1007 / \mathrm{s} 00585-996-0917-6$.

Huang, X., B.W. Reinisch, and D. Bilitza (2001), IRI in Windows environment, Adv. Space Res. 27, 1, 127-131, DOI: 10.1016/S0273-1177(00)00148-4.

ITU-R (1997), ITU-R Recommendations, Vol. 1997, P Series - Part 1, International Telecommunication Union, Geneva, Switzerland.

Ivanov-Kholodny, G.S., and A.V. Mikhailov (1986), The Prediction of Ionospheric Conditions, Geophysics and Astrophysics Monographs, D. Reidel Publ. Co., Dordrecht.

Jakowski, N., S. Schlüter, and E. Sardon (1999), Total electron content of the ionosphere during the geomagnetic storm on 10 January 1997, J. Atmos. Sol.Terr. Phys. 61, 3-4, 299-307, DOI: 10.1016/S1364-6826(98)00130-8.

Jakowski, N., C. Mayer, M.M. Hoque, and V. Wilken (2011), Total electron content models and their use in ionosphere monitoring, Radio Sci. 46, 6, RS0D18, DOI: $10.1029 / 2010 R S 004620$. 
Kamide, Y. (2000), From discovery to prediction of magnetospheric processes, J. Atmos. Sol.-Terr. Phys. 62, 17-18, 1659-1668, DOI: 10.1016/S13646826(00)00118-8.

Mannucci, A.J., O.P. Verkhoglyadova, B.T. Tsurutani, X. Meng, X. Pi, C. Wang, G. Rosen, E. Lynch, S. Sharma, A. Ridley, W. Manchester, B. Van Der Holst, E. Echer, and R. Hajra (2015), Medium-range thermosphereionosphere storm forecasts, Space Weather 13, 3, 125-129, DOI: 10.1002/ 2014SW001125.

Matsushita, S. (1959), A study of the morphology of ionospheric storms, J. Geophys. Res. 64, 3, 305-321, DOI: 10.1029/JZ064i003p00305.

McNamara, L.F., G.J. Bishop, and J.A. Welsh (2011), Analog ionospheric forecasts: Space weather forecasts by analogy with previous events, Radio Sci. 46, 1, RS1002, DOI: 10.1029/2010RS004399.

Mendillo, M. (2006), Storms in the ionosphere: Patterns and processes for total electron content, Rev. Geophys. 44, 4, RG4001, DOI: 10.1029/2005RG000193.

Mikhailov, A.V., L. Perrone, and N.V. Smirnova (2012), Two types of positive disturbances in the daytime mid-latitude F2-layer: Morphology and formation mechanisms, J. Atmos. Sol.-Terr. Phys. 81-82, 59-75, DOI: 10.1016/j.jastp. 2012.04.003.

Millward, G.H., H. Rishbeth, T.J. Fuller-Rowell, A.D. Aylward, S. Quegan, and R.J. Moffett (1996), Ionospheric F2 layer seasonal and semiannual variations, J. Geophys. Res. 101, A3, 5149-5156, DOI: 10.1029/95JA03343.

Mukhtarov, P., B. Andonov, and D. Pancheva (2013), Global empirical model of TEC response to geomagnetic activity, J. Geophys. Res. 118, 10, 66666685, DOI: $10.1002 /$ jgra.50576.

Musman, S., G. Mader, and C. Everett Dutton (1998), Total electron content changes in the ionosphere during the January 10, 1997 disturbance, Geophys. Res. Lett. 25, 15, 3055-3058, DOI: 10.1029/98GL51785.

Namgaladze, A.A., M. Förster, and R.Y. Yurik (2000), Analysis of the positive ionospheric response to a moderate geomagnetic storm using a global numerical model, Ann. Geophys. 18, 4, 461-477, DOI: 10.1007/s00585-0000461-8.

Pezzopane, M., M. Pietrella, A. Pignatelli, B. Zolesi, and L.R. Cander (2011), Assimilation of autoscaled data and regional and local ionospheric models as input sources for real-time 3-D International Reference Ionosphere modeling, Radio Sci. 46, 5, RS5009, DOI: 10.1029/2011RS004697.

Pezzopane, M., M. Pietrella, A. Pignatelli, B. Zolesi, and Lj.R. Cander (2013), Testing the three-dimensional IRI-SIRMUP-P mapping of the ionosphere for disturbed periods, Adv. Space Res. 52, 10, 1726-1736, DOI: 10.1016/j.asr. 2012.11.028.

Pietrella, M. (2012), A short-term ionospheric forecasting empirical regional model (IFERM) to predict the critical frequency of the F2 layer during moderate, disturbed, and very disturbed geomagnetic conditions over the European area, Ann. Geophys. 30, 2, 343-355, DOI: 10.5194/angeo-30-343-2012.

Pietrella, M., and L. Perrone (2008), A local ionospheric model for forecasting the critical frequency of the F2 layer during disturbed geomagnetic and iono- 
spheric conditions, Ann. Geophys. 26, 2, 323-334, DOI: 10.5194/angeo-26323-2008.

Piggott, W.R., and K. Rawer (1972), U.R.S.I. handbook of ionogram interpretation and reduction, Report UAG-23, National Oceanic and Atmospheric Administration, Boulder, Colorado.

Prölss, G.W. (1995), Ionospheric F-region storms. In: H. Volland (ed.), Handbook of Atmospheric Electrodynamics, Vol. 2, CRC Press, Boca Raton, 195-248.

Reilly, M.H., F.J. Rhoads, J.M. Goodman, and M. Singh (1991), Updated climatological model predictions of ionospheric and HF propagation parameters, Radio Sci. 26, 4, 1017-1024, DOI: 10.1029/91RS00583.

Rishbeth, H. (1991), F-region storms and thermospheric dynamics, J. Geomagn. Geoelectr. 43, Suppl. 1, 513-524, DOI: 10.5636/jgg.43.Supplement1_513.

Rishbeth, H., I.C.F. Müller-Wodarg, L. Zou, T.J. Fuller-Rowell, G.H. Millward, R.J. Moffett, D.W. Idenden, and A.D. Aylward (2000), Annual and semiannual variations in the ionospheric F2-layer: II. Physical discussion, Ann. Geophys. 18, 8, 945-956, DOI: 10.1007/s00585-000-0945-6.

Smithtro, C.G., and J.J. Sojka (2005), Behavior of the ionosphere and thermosphere subject to extreme solar cycle conditions, J. Geophys. Res. 110, A8, A08306, DOI: 10.1029/2004JA010782.

Strangeways, H.J., I. Kutiev, Lj.R. Cander, S. Kouris, V. Gherm, D. Marin, B. De La Morena, S. Eleri Pryse, L. Perrone, M. Pietrella, S. Stankov, L. Tomasik, E. Tulunay, Y. Tulunay, N. Zernov, and B. Zolesi (2009), Near-Earth space plasma modelling and forecasting, Ann. Geophys. 52, 3-4, 255-271, DOI: 10.4401/ag-4579.

Vijaya Lekshmi, D., N. Balan, S. Tulasi Ram, and J.Y. Liu (2011), Statistics of geomagnetic storms and ionospheric storms at low and mid latitudes in two solar cycles, J. Geophys. Res. 116, A11, A11328, DOI: 10.1029/ 2011 JA017042.

Wilkinson, P., J. Wu, J. Du, and Y.-J. Wang (2001), Real-time total electron content estimates using the International Reference Ionosphere, Adv. Space Res. 27, 1, 123-126, DOI: 10.1016/S0273-1177(00)00147-2.

Zolesi, B., and L.R. Cander (2014), Ionospheric Prediction and Forecasting, Springer Geophysics, Springer, Berlin Heildelberg, DOI 10.1007/978-3642-38430-1.

Zolesi, B., Lj.R. Cander, and G. De Franceschi (1993), Simplified ionospheric regional model for telecommunication applications, Radio Sci. 28, 4, 603612, DOI: 10.1029/93RS00276.

Received 21 April 2015

Received in revised form 14 September 2015

Accepted 17 September 2015 